TRAMES, 2010, 14(64/59), 1, 54-70

\title{
THE RELATIONSHIP OF TEXT FEATURES TO THE LEVEL OF INTEREST IN SCIENCE TEXTS
}

\author{
Jaan Mikk and Hasso Kukemelk
}

University of Tartu

\begin{abstract}
Two studies were conducted to explore the connection between science texts features and students' ratings of the interest level of the texts. In both studies, students from the 8th-10th grade completed a knowledge test prior to reading, studied the texts, and rated the texts in terms of interest. In the first study, 124 students each worked with 48 popular scientific texts in biology. In the second study, 400 students worked with 40 texts from physics textbooks. The students indicated higher interest in texts with fewer abstract words and scientific terms, shorter sentences and words and a lower repeating rate for nouns. Frequent words in spoken language were related to lower interest in textbooks, but higher interest in popular scientific texts. This difference in the results may be attributed to the higher prior knowledge of textbooks (26\%) compared to their knowledge of popular scientific texts $(6 \%)$. Implications of the findings are discussed.
\end{abstract}

Keywords: text-based interest, biology, physics, noun concreteness, word familiarity, text analysis

DOI: $10.3176 /$ tr.2010.1.04

\section{Introduction}

Interest in texts is an important facilitator and result of learning (Alexander 2003, Alexander, Kulikowitch, and Schulze 1994, Bray and Barron 2004, Guthrie et al. 2007, Hidi 2001, Jetton and Alexander 2001). In the study by Dai and Wang (2007), the correlation between comprehension and interest was .23 to .57 and in the investigation by Alexander, Jetton, and Kulikowitch (1995) from .40 to .63. By analyzing 36 studies, Schiefele (1999) reached a correlation of .27 between personal interest and text learning and a correlation of .33 between situational interest and learning. The connection appeared to be stronger for deep learning than surface-level learning. Singh, Granville, and Dika (2002) examined the effects of motivation, attitude and academic engagement on achievement among 
3227 students in the eighth grade. The effect of attitude, including interest, was .34 and this influenced science achievement in terms of academic time.

Many researchers have studied the features of texts that encourage interest. The sources of interest in texts have been found to be novelty of content, unexpected or surprising information, concreteness, visual imagery, ease of comprehension, text cohesion, vividness, personal engagement, etc. (Hidi 2001, Jetton and Alexander 2001, Schraw, Flowerday, and Lehman 2001).

Alexander and Jetton (1996) wrote that narrative texts are more interesting than expository ones. Expository texts are seldom related to the students' long-term interests and many readers have little domain knowledge to make understanding expository texts as easy as narrative texts. Narrative texts have a familiar structure, which facilitates comprehension.

Sadoski, Goetz, and Rodriguez (2000) investigated the effects of concreteness on comprehensibility and interest in four text types: persuasive, expository, literary stories and narratives. They asked students to assess the familiarity, interest level, etc. of text passages. Text interest correlated strongly with text concreteness (.85), comprehensibility (.85), and familiarity (.71). The corresponding path coefficients were lower: the effect of concreteness on interest was .44 , of comprehensibility .37, and the effect of familiarity was .07.

Stories about people make texts concrete and interesting and so Flesch (1948) elaborated a formula that enabled him to calculate the index of Human Interest relying on the percentage of personal words and personal sentences in the text. Personal words are words denoting people and pronouns that refer to people. Personal sentences are sentences in quotation marks, questions, requests, exclamations, and grammatically incomplete sentences. However, the coefficient of the multiple correlation of the formula was only .43 .

One way to include people in science textbooks is to give historical data. Rodrigues and Niaz (2004) wrote that textbook presentations based on a history of science can arouse student interest. Baumann (1980) investigated the efficiency of including historical circumstances in a chemistry textbook, and his students in the sixth grade evaluated the texts with the history of discoveries as the most interesting.

Hidi and Baird (1988) have investigated the strategies for increasing text-based interest. They added salient descriptive elaborations and questions that need resolution to expository texts. Fourth and sixth grade students evaluated the new texts as more interesting than basic texts, but the recall of scientific information remained at the same level.

Alexander and Jetton (1996) reviewed the literature on seductive details in expository texts. They concluded that vivid anecdotes, lively quotations, and so on raise the students' level of interest in the texts, but these elements have a negative effect on the processing of the main content of the text. This result can be explained using cognitive load theory (Leahy, Cooper and Sweller 2004, Sweller, Merriënboer and Paas 1998), which elucidates that interesting and emotional elements in a text may require a significant part of the capacity of working 
memory and, therefore, the processing of the main content of the text is disturbed. Later Sadoski (2001) concluded that there is no reason to include seductive details in a text.

Baumann (1980) has studied the effect of rating textbook content positively in the text. He included different ratings in the text; for example, we will study the beneficial upstream principle or we will study the economically beneficial and technically approved upstream principle. Students studied the texts with different ratings and filled in post-tests. The ratings for one- two words were the most effective: the acquisition level increased by up to 50\%. However, positive ratings using full sentences even decreased the level of text acquisition. Textbook authors should be careful when including positive ratings in a text.

The level of interest in a text was mainly studied at the level of entire passages: expository versus narrative texts, the inclusion of historical data, etc. The connection between text interest and its features at the micro-level is rarely studied.

The aim of the study was to find word and sentence level features of text that are related to interest in science texts. Interest in popular scientific texts in biology and textbooks for physics was studied.

Four hypotheses were examined in both studies:

1. We hypothesized that the percentage of concrete words should be related to text interest. The hypothesis is derived from the research by Sadoski, Goetz and Rodriguez (2000) who found strong connections between concreteness ratings and interest ratings. For the same reason, we hypothesize that the percentage of abstract words is related to low interest in science texts.

2. Alexander and Jetton (1996) have found that narrative texts are more interesting than expository ones that usually include many unfamiliar words. Sadoski, Goetz and Rodriguez (2000) concluded that familiar texts are more interesting. Therefore, we will seek the correlates of text interest in the indices of word familiarity and, first of all, according to their frequency in language.

3. Laukenmann et al. (2003) have found that interest is related to success in learning. Success may be hindered by long sentences and long words that are often difficult to understand. We hypothesize that the indices of sentence length and word length should be related to text interest.

4. A specific feature of science texts is the availability of scientific terms and symbols that are usually unfamiliar and abstract. For the reasons above, we hypothesize that a high percentage of scientific terms and symbols leads to texts of a low interest level.

Different ways for measuring the above mentioned features of texts will be tested in the studies below.

The research design in the two studies was the same. Students studied 48 texts in biology and 40 texts in physics and rated the interest level of the texts. On the other hand, numerical values of different text features were found. The connection between the features of texts and their interest level was characterized by linear correlation coefficients and effect size. Correlation coefficient $r$ between the values of every text feature and interest ratings to the texts was calculated. The 
size of the effect of every feature was calculated according to the formula $d=r / \sqrt{ }\left(1-r^{2}\right)$ (Furr 2008:6). Only correlation coefficients significant at the 0.05 level were considered in this step.

\section{A study of popular scientific texts in biology}

\subsection{Method}

Subjects - one hundred and twenty four students of mixed socio-economic status participated in the first study. The students were 15-16 years old and they studied in Russian speaking schools in a city in Estonia. Russian was the mother tongue of the students and they studied all their school subjects in Russian. The students studied in five classes that were composed without any selection from the children of the school catchment area.

The texts for the study were taken from popular scientific books and papers suitable for the age group. The topics of the texts were different from the ones dealt with in the school curricula to avoid the effect of studying the topic of some texts beforehand in school. There were not more than two texts taken from one book in order to achieve greater variety in the content and style of the texts in the study. The texts covered different areas in biology: life of animals and birds, plants, biological processes and organs, and cells. In this way, the texts covered the macro-level in biology, biological processes, and the micro-level in biology. Forty-eight texts, each on a single typewritten page, were used in the study. The texts included neither formulae nor illustrations.

Content tests were composed to test the knowledge of text content before and after studying them. The tests on every text were composed in four variants each including six to ten free-response questions. The questions were aimed at recalling concepts and facts, at expressing connections, explaining phenomena, etc. A large number of questions was needed to cover all the content of the texts. The same tests served as pre-test and post-test.

Procedure - every student worked with every text without any support from teachers or co-students. The students were given a version of the content test before reading the text. All four versions of the test were in use as the pre-test. After delivering the answers to the teacher, the students received corresponding texts to read. The students studied the texts, returned them to the teacher and received a questionnaire in which they were asked about the difficulty of the text, interest when reading it, and willingness to continue reading the text. Finally, the students took a post-test that was a different version from the four versions of the content test. While the same four versions served as pre-test and post-test, the average difficulty level of the pre- and post-test is the same. Different students worked with different texts in each class. The inter-scorer reliability for scoring the free-response questions was .85. The average score was calculated for the prior test result, interest rating and post-test for every text. The student's work with one text took up to one lesson and so the study lasted 48 lessons. 
The questions about the difficulty and interest level of the texts were as follows.

1. The text was for me

$\square$ easy

$\square$ difficult

2. The text was

$\square$ interesting

$\square$ not interesting

3. I would

$\square$ like

$\square$ not like

to continue reading the text

The answers were coded using "1" and "2" with the higher number indicating a positive attitude to the text. The average rating for each text was calculated and the reliability of the interest ratings was found as the correlation between average interest ratings and willingness to continue reading ratings. The reliability of the average interest ratings was 98 .

The analysis of the texts was carried out on computers. All the texts in the study were typed into a computer and a computer program counted the number of characters in words and the number of words in sentences. This data was needed to test the third hypothesis. Another computer program transformed the word forms in our texts into their main form, established the parts of speech of the words and composed a dictionary of the words in the texts ${ }^{1}$. For further analysis, the frequency dictionary for words in the Russian spoken language was used ${ }^{2}$. The computer found the frequency of the words in our texts in the frequency dictionary of spoken language and calculated the average frequency of the text words in the dictionary and other text characteristics to test the second hypothesis.

To verify the first and last hypothesis, a special list of noun abstractness and their being a scientific term was used. The computer composed the list of nouns in all the texts and a specialist assessed their level of abstractness and the level of being a term in biology texts. The specialist had a good knowledge of biology and was trained in using the scales.

Noun abstractness was assessed according to the following three-stage scale:

1 - nouns signifying directly perceivable objects (e.g. tree, dog),

2 - nouns signifying perceivable activities and phenomena (e.g. the blooming, sunshine),

3 - nouns signifying directly imperceptible notions (e.g. cause, function).

The first category contains concrete nouns, and the last category abstract nouns.

1 The computer program was worked out in Kiev by N. A. Darčuk and colleagues and kindly delivered to us.

2 The frequency dictionary was composed in Moscow University by D. Buchštab and colleagues and kindly delivered to us in electronic form. 
The nouns in the texts were divided into three categories according to their scientific level:

1 - nouns from everyday use that are not terms (table, horse),

2 - scientific terms with the same meaning in everyday speech (biology, acceleration),

3 - professional terms not used in everyday speech (DNA, transcription).

After the levels for every noun were put into the computer, it calculated the average abstractness of the words and the percentage of concrete and abstract nouns in every text. Similar calculations were made to find the percentage of professional terms and the percentage of everyday nouns in every text.

The reliability of applying the scales was assessed using the test-retest method. A specialist trained in using the scales rated the abstractness level of nouns and their scientific level in a text including 128 nouns. A year later, he rated the levels once more without looking at the first ratings. The correlation between the first and second ratings was .88 for abstractness. The intra-rater reliability of marking nouns from everyday use that are not terms was .80 and the reliability of marking professional terms not used in everyday speech was .93 .

Although scientific terms are often abstract nouns, the correlation between noun abstractness and their terminological level is about .4 (Elts 1995). Therefore, both indicators are important in characterizing texts.

\subsection{Results and discussion}

The texts were 258 words $(\mathrm{SD}=29)$ or 1915 character spaces long $(\mathrm{SD}=130)$ on average. The mean abstractness of nouns was 1.81 on three-stage scale $(\mathrm{SD}=.35)$. The sentences in the popular scientific texts were 15.8 words long $(\mathrm{SD}=4.1)$.

Students answered $5.5 \%$ of questions correctly before reading the texts $(\mathrm{SD}=$ 5.5). The average interest rating was $1.53(\mathrm{SD}=.25)$ and the average willingness to continue reading was $1.45(\mathrm{SD}=.22)$ on two-stage scale. The correlation between prior knowledge of text content and text interest was .68. The texts on more familiar topics enable success in the learning process and this supports interest (Jetton and Alexander 2001, Laukenmann et al. 2003). The average level of correct answers was $36.2 \%$ in the post-test $(\mathrm{SD}=16.0)$.

Text abstractness was related to the level of interest in the text (Table 1). The percentage of abstract nouns had the highest effect on text interest ratings in the study. The higher the percentage of abstract nouns in the text, the lower the interest in learning the text. An abstract text evokes fewer images and it is difficult to understand. Alexander et al. (1995) wrote that a more imaginable text includes more concrete nouns that had a positive effect on text interest in our study. Sadoski et al. (2000) have used text concreteness ratings and also found a positive correlation between text concreteness and interest.

The students found that the texts that included more words outside the spoken language dictionary or more rare words were less interesting (Table 2). In the same vein, students found texts more interesting when they contained nouns that 
Table 1. The connection between abstractness and interest in popular scientific texts

\begin{tabular}{l|c|c}
\hline \multicolumn{1}{c|}{ Characteristic } & $\mathrm{r}$ & $\mathrm{d}$ \\
\hline Percentage of concrete nouns & .54 & .64 \\
Mean abstractness of nouns & -.62 & -.79 \\
Percentage of abstract nouns & -.70 & -.98 \\
\hline
\end{tabular}

Table 2. The connection between word familiarity and interest in popular scientific texts

\begin{tabular}{l|r|r}
\hline \multicolumn{1}{c|}{ Characteristic } & \multicolumn{1}{c}{$\mathrm{r}$} & \multicolumn{1}{c}{$\mathrm{d}$} \\
\hline Percentage of words outside the frequency dictionary of spoken language & -.49 & -.56 \\
Percentage of rare words (less than 80 times in the frequency dictionary) & -.64 & -.83 \\
Percentage of rare nouns (less than 80 times in the frequency dictionary) & -.51 & -.59 \\
Average frequency of the text's nouns according to the spoken language dictionary & .50 & .58 \\
Repeating rate of the nouns in the text & -.48 & -.55 \\
Percentage of nouns in the text & -.63 & -.81 \\
\hline
\end{tabular}

were more frequently used in spoken language. Frequent words in spoken language were related to the students' experiences, and students found it interesting to read about things that were familiar to them.

However, when nouns were repeated in a text 1.35 times $(\mathrm{SD}=.13)$, on average, this hindered interest even at such a modest repetition rate. The repeat rate of all words was also 1.35 ( $\mathrm{SD}=.08$ ), but it was not related to interest in the text. The recurrence of conjunctions, pronouns and so on, is expected, but the iteration of the most important content words is boring.

Linguists normally do not approve of the intensive use of nouns in a text. We find support for this in Table 2 according to which the high percentage of nouns in the texts had a strong negative connection to interest in learning.

The percentage of sentences over 109 characters with spaces was also negatively related to text interest, while average sentence length only had a medium connection with text interest (Table 3). The measurement of sentence length in characters results in data with higher predictive validity than measurement in words. Texts that use shorter sentences include more verbs and this explains why a high percentage of verbs facilitated interest in a text.

Table 3. The connection between word length, sentence length, and interest in popular scientific texts

\begin{tabular}{lrr}
\hline \multicolumn{1}{c|}{ Characteristic } & \multicolumn{1}{c|}{$\mathrm{r}$} & \multicolumn{1}{c}{$\mathrm{d}$} \\
\hline Percentage of sentences over 109 characters with spaces & -.72 & -1.04 \\
Percentage of sentences over 15 words & -.55 & -.66 \\
Sentence length in words & -.54 & -.64 \\
Percentage of verbs in the text & .49 & .56 \\
Percentage of words over 13 characters & -.58 & -.71 \\
Word length in characters & -.75 & -1.14 \\
\hline
\end{tabular}


The percentage of long words (with 14 or more characters) was higher in texts with low interest ratings (Table 3). These words are infrequent in language and often rather abstract (Elts 1995). So, the result is in accordance with the data in Tables 1 and 2 according to which abstract words and rare words are related to low interest in a text.

Professional terms created a considerable reduction of interest in the text (Table 4). The terms are usually unknown to students and therefore difficult to learn. On the other hand, everyday nouns, which were not terms, were connected to high text interest. The percentage of professional terms in a text should be kept to a lower level to retain the students' interest in a popular scientific text.

Table 4. The connection between terms, symbols, and interest in popular scientific texts

\begin{tabular}{lrr}
\hline \multicolumn{1}{c|}{ Characteristic } & $\mathrm{r}$ & \multicolumn{1}{c}{$\mathrm{d}$} \\
\hline Percentage of professional terms not used in everyday speech & -.71 & -1.01 \\
Percentage of everyday nouns & .49 & .56 \\
Percentage of abbreviations and symbols among words & -.33 & -.35 \\
\hline
\end{tabular}

Abbreviations and symbols are special signs to be learnt to understand the text easily. The percentage of signs was low in the texts studied (1\%); however, interest in the texts with many special signs and abbreviations was low. We should not reduce our readers' interest by including unknown abbreviations and symbols in a text.

Altogether about 200 characteristics of the texts were used. Many of them differed from each other in details; for example, the percentage of words with 12 or more characters, with 13 or more characters etc. Only the characteristics with the highest and statistically significant correlation coefficients were given in the tables above. The characteristics were the best for predicting interest level of a popular scientific text in biology. The connection of the characteristics to text interest proved all the hypotheses in this study.

\section{A study of physics textbooks}

The texts in the first study were unrelated to each other in their content. The second study was organized differently in this respect; that is, texts were related to each other and students had always acquired the section before the one in the study.

\subsection{Method}

Subjects - 393 students from 13 Russian-speaking schools in Estonia participated in the study. The 16-17-year old students studied in the ninth and tenth grade. They were of mixed socio-economic status and there was no selection of students for the classes or the study. The students were of average achievement 
levels and were taught by experienced teachers. The schools were located in cities, and there were 30 students in a class on average. Russian was the mother tongue of the students and they studied all their school subjects in Russian.

Texts - forty sections were taken from physics textbooks for the ninth and tenth grade. The texts served as the material for the study and covered different topics: electron theory, magnetism, mechanical and electrical oscillations, the production of electricity, and mechanical and electrical waves. The texts included explanations of scientific terms, information about physics phenomena and laws, and the connection between physics theory and everyday life. The texts were on average 1.8 pages long.

Tests were composed to measure knowledge of the content of every text. The tests included free response questions, multiple-response questions and sentences with blanks. The questions were aimed at recalling information in text, transforming the information from verbal form to graphic form and vice versa, and solving problems. Altogether, 80 questions were composed for every text and the questions were divided between eight versions of the test for each text. We needed so many questions to better cover the content of the texts.

Procedure - the texts were studied by the students at the time they reached that section in their learning schedule. Every section was studied in a lesson of 45 minutes, and the next section was studied one-two lessons later, on average. The procedure in every lesson was the same as in the first study. The study lasted 40 lessons over one school year.

After studying the texts, students filled in a questionnaire, which included the following item:

The text was for me

$\square$ not interesting,

$\square$ interesting.

The answers were coded using "1" and "2" and the average answer from 393 students served to rate the interest level of the text.

All eight versions of the content test were used as a pre-test. Every student filled in one version in the pre-test. In the post-test, the same versions were used and every student filled in another version of the content test. As far as the same tests were used as pre-and post-test throughout the entire group of students, the difficulty of the pre- and post-tests was the same.

Students studied the texts independently. Their teachers gave no explanations and students were not allowed to consult with each other. After finishing the posttest, consultations and teacher explanations of the content were designed to ensure a proper understanding of the study material.

The analysis of texts was carried out mostly on computers as in the previous study with some differences. The list of the most frequent words in the Russian language (4000 najbolee...) was used in addition to the spoken language frequency dictionary. The terms in the texts were identified according to the frequency dictionary of scientific-technical words (Denisov, Morkovkin, and Safyan 1978) instead of the three-stage scale for nouns as terms. L. Vassilchenko 
composed the frequency dictionary of nouns in the series of physics textbooks used in schools and the frequency of our text nouns in the previous physics textbooks was calculated. The test-retest reliability of the assessment of noun abstractness was .92.

\subsection{Results and discussion}

The texts included, on average, 499 words ( $\mathrm{SD}=168)$. The average abstractness of nouns $(2.0)(\mathrm{SD}=.20)$ and the average length of sentences (13.1 words) $(\mathrm{SD}=1.5)$ were the same as in the physics textbooks indicating that the study texts were representative of all physics textbooks. Students correctly answered $26.1 \%$ of all questions before reading the texts $(\mathrm{SD}=6.9)$. The average interest rating was $1.55(\mathrm{SD}=.16)$ and the average post-test score for all the texts was $54.4 \%$ $(\mathrm{SD}=10.7)$.

Text abstractness was characterized by the abstractness of nouns and by nouns with abstract suffixes. The latter had no effect on text interest level, but noun abstractness, according to the three-stage scale, resulted in statistically significant connections (Table 5). The more the physics textbook sections included abstract nouns the less the students were interested in studying the text.

Table 5. The connection between text abstractness and interest in textbooks

\begin{tabular}{lc|c}
\hline \multicolumn{1}{c|}{ Text feature } & $\mathrm{r}$ & $\mathrm{d}$ \\
\hline Average abstractness of nouns in a section & -.52 & -.61 \\
Percentage of abstract nouns & -.48 & -.55 \\
\hline
\end{tabular}

One of our hypotheses was that the texts that include more words that are frequent in the language, more words from spoken language and more words from the sections of physics textbooks, are more interesting. The hypotheses were not supported in the study (Table 6).

An unexpected result was that using nouns that are frequent in the language led to lower interest $(\mathrm{d}=-.66)$. To explain this result, we can say that the vocabulary of the students of the 9th -10 th grades is rather well developed and they would be

Table 6. The connection between text familiarity and interest in textbooks

\begin{tabular}{lrr}
\hline Text feature & $\mathrm{r}$ & $\mathrm{d}$ \\
\hline Percentage of nouns from the list of the 4,000 most frequent words in the language & -.55 & -.66 \\
Percentage of nouns outside the frequency dictionary of spoken language & .48 & .55 \\
Percentage of rare nouns (less than 80 times in the frequency dictionary of spoken & .35 & .37 \\
language) & -.37 & -.40 \\
Frequency of section nouns in spoken language & -.69 & -.95 \\
Average section noun occurrence in the physics textbook for the 9th grade & -.70 & -.98 \\
Average section noun occurrence in the physics textbooks & -.72 & -1.04 \\
Repeating rate for words in the section & & \\
\hline
\end{tabular}


bored if they only read the most frequent words in the language. The other text feature in Table 6 supports this explanation. The more nouns in the passages outside the spoken language frequency dictionary, the more interesting the sections became. Infrequent nouns made the textbooks interesting, but not infrequent words in general.

Textbook authors may try to use the same nouns repeatedly to facilitate text comprehension; however, this may significantly reduce the students' interest in the section. Frequent nouns in textbooks were boring for students as was a high repeat rate for words $(\mathrm{d}=-1.04)$ (Table 6$)$.

Frequent words are usually shorter and so we can conclude from the above that the high percentage of short words in a textbook should result in lower interest. This conclusion contradicts our initial hypothesis that texts written using shorter words should be more interesting, but it is supported by the connection between long nouns and high interest ratings in textbooks (Table 7). Despite these findings, the initial hypothesis appears in the fact that average word length had no statistically significant connection to interest in the text.

Table 7. The connection between word length, sentence length, and interest in textbooks

\begin{tabular}{lr|r}
\hline Text feature & $\mathrm{r}$ & $\mathrm{d}$ \\
\hline Percentage of long nouns (14 or more characters) & .36 & .39 \\
Average sentence length in characters & -.40 & -.44 \\
Percentage of verbs in the text & .35 & .37 \\
Percentage of short sentences (up to 17 words) & .45 & .50 \\
\hline
\end{tabular}

Three text features in Table 7 supported the hypothesis that shorter sentences are connected to higher interest in the text. This connection was weak, and the highest among them was seen by the percentage of sentences up to 17 words. The upper limit of short sentences was found using different lengths in the calculations: 5 words, 7 words, ... 29 words. The 17-word upper limit in sentence length resulted in the strongest connection. The weaker connection by lower limits may be caused by the fact that, in this case, in the calculations some easily processed sentences are incorrectly included as difficult sentences (Mikk 2008). Sentences with a length of up to 17 words were the most suitable for writing interesting texts in physics textbooks for 15 - 16-year old students.

Table 8. The connection between symbols, formulae, terms, and interest in textbooks

\begin{tabular}{lcc}
\multicolumn{1}{c|}{ Text feature } & $\mathrm{r}$ & $\mathrm{d}$ \\
\hline Number of numerals, symbols, formulae, and abbreviations in 100 words & -.50 & -.58 \\
Number of symbols in 100 words & -.52 & -.61 \\
Number of formulae in 100 words & -.54 & -.64 \\
Percentage of scientific-technical nouns & -.64 & -.83 \\
\hline
\end{tabular}


Science has its own special language - scientific terms, symbols etc. - that reduce interest in the text (Table 8). The higher the percentage of scientific terms, formulae, symbols, and abbreviations, the lower the students' interest ratings for the text. Scientific-technical nouns, which were identified in the text using the dictionary of scientific-technical words (Denisov et al. 1978), showed the strongest connection.

Here we see once more the contradiction between the need to deliver new scientific content and the desire to write an interesting text. Scientific terms, formulae, abstract words, and even long sentences are needed to properly deliver new and complicated content, but all these features usually make the text less interesting. Text authors have to find the optimal way between the two important but different goals.

Altogether about 400 characteristics of texts were considered in the study and only the most valid in predicting text interest were given in Tables $5-8$. The results of the study prove three hypotheses, but the hypothesis about texts with more familiar words being more interesting was not supported in the case of textbooks.

\section{General discussion}

The students' interest in expository science texts was studied from the perspective of concreteness, familiarity, sentence and word length, and terms and symbols. Human interest factors, illustrations, tasks for students were not the object of the study.

In the study of popular scientific texts, the contents of different texts were not related to each other, but textbooks were investigated in a realistic school situation - students studied the texts according to their curricula. The contrast may explain the significant difference in the average prior knowledge and post-test score of students. The students knew almost nothing (only 5.5\%) about the content of the popular scientific texts before reading them, but the students' prior knowledge of the textbooks was $26 \%$. The post-test score in the study of textbooks $(54.4 \%)$ was considerably higher than the post-test score in the study of popular scientific texts $(36.2 \%)$.

The correlation between the prior knowledge of text content and interest ratings was .68 in the first study. This correlation is in accordance with the findings of Alexander and Jetton (1996) and Tobias (1995), who wrote that higher prior knowledge also enhances interest in the text. If students can connect the text with their experience, they have positive emotions. Laukenmann et al. (2003) conclude that the joy of learning and interest are frequently linked to success in learning.

The students' prior knowledge of the content of the textbooks was higher and therefore higher interest ratings for the sections from physics textbook are also expected (Garner et al. 1991, Jetton and Alexander 2001). However, the average interest rating was 1.53 for biology texts and 1.55 for physics texts. An explanation of the equality of the average ratings lies in the fact that passages from 
physics textbooks were more abstract than the popular scientific texts in biology (average abstractness of physics texts was 2.0 and biology text 1.81) and abstractness of physics texts reduces their interest.

The hypothesis about the connection between concreteness and interest was supported in both studies. The negative correlation between the percentage of abstract nouns and text interest was .48-.70 (Tables 1 and 5). A high correlation between text concreteness and interest has also been found by Sadoski et al. (1993, 2000).

The role of word familiarity was different in popular scientific texts and textbooks. In textbooks, the words outside the spoken language dictionary facilitated interest in the text (Table 6). In popular scientific texts, the words outside the spoken language dictionary reduced the interest in the text (Table 2). The different roles of word familiarity are related to the different level of prior knowledge of the content of textbooks and popular scientific texts. The content of the sections in textbooks was relatively familiar to the students, and, in this case, the words outside the spoken language dictionary were of interest to the students. The content of popular scientific texts was unknown to students, and the words, seldom used in spoken language, added difficulties in text comprehension and reduced text interest.

The familiarity of words is an indicator of the familiarity of text content. People know the topics that interest them better (Tobias 1995). Campos, Marcos, and Gonzalez (2002) studied interest and the other features of Spanish words. Interest proved to have a significant correlation with the familiarity of words. On the other hand, the connection does not hold for familiar texts, in which some unknown words may arouse the students' interest.

In both studies, the texts with the higher rate of word repetition were less interesting for students (Tables 2 and 6). People do not like to continually read the same words, and therefore, text authors should take care with the variability of examples, conceptual aspects and so on, in their writing. At the same time, scientific terms should not be replaced by everyday words.

The hypotheses about sentence length and word length were supported in both studies. The texts with longer words and longer sentences were less interesting for students as a rule (Tables 3 and 7). At the same time, the proportion of long sentences had a stronger connection with interest than average sentence length had in both studies. Long sentences may be more harmful for text interest than increasing the average sentence length.

The relationship of word length and sentence length with text interest was stronger in the popular scientific texts than in the textbooks (Tables 3 and 7). For example, in textbooks, the average word length had no statistically significant correlation with text interest, but in popular scientific texts the correlation was .75. The stronger connection in the popular scientific study can be explained by the lack of prior knowledge of popular scientific texts. If student knowledge of the text content is low then the comprehensibility of the text is very important in increasing interest in the text. Unknown content plus long words and sentences 
may overload the working memory of readers and even evoke negative emotions. The described regularity enfolds other features of texts as well (average abstractness of nouns, percentage of verbs, nouns infrequent in spoken language, etc.) by which the effect in popular scientific texts was about .2 larger than in textbooks.

Symbols and abbreviations in the text resulted in a low interest in the texts in both studies (Tables 4 and 8). The connections were stronger for sections in textbooks that had more symbols, abbreviations, formulae, etc. Even one percent of symbols and abbreviations in the popular scientific texts was related to lower interest ratings in these texts.

The high percentage of scientific terms was related to lower interest up to one standard deviation in both studies (Tables 4 and 8). The texts with many terms are usually less familiar to students, and therefore less interesting. Scientific terms are sometimes abstract words; however, both of these text features were equally important in predicting text interest.

Lawless and Kulikowich (2006) have found that the positive connection between domain knowledge and individual interest increases as a student progresses in learning. Our last finding differs from their conclusion; namely, lesser knowledge of text content increased the role of text features in forming interest. However, there is no contradiction. We considered prior knowledge of the text under study, and they considered domain knowledge.

The correlates of text interest can indicate ways to enhance interest. For example, Sadoski et al. (2000:93) concluded that “...using more concrete language and content should have positive effects in making sentences and paragraphs of texts more comprehensible, interesting and memorable...". Later Sadoski (2001:275) wrote that "...general principles need to be fleshed out with clearly connected concrete examples." The present research adds that avoiding scientific terms, variations in word usage and writing in shorter sentences should also raise interest in the text. The effect may be rather impressive according to Tables 1-8. However, the recommendations should be followed carefully because the content of science texts presupposes using some terms and abstract nouns.

Analogous recommendations for enhancing text comprehension have been effective in most cases studied, but not always (Klare 1963). Therefore, we have to be careful about offering recommendations for an interesting style from Tables 1-8. Let us give an example. The recommendation to write in concrete words may lead the author to including examples. However, if the examples are irrelevant to the text content they serve as seductive details. The research on seductive details is full of controversies (Sadoski 2001), but most authors posture that seductive details hinder the acquisition of knowledge from the text (Alexander and Jetton 1996, Garner et al. 1991, Harp and Maslich 2005, Harp and Mayer 1997, Lehman et al. 2007). Alexander et al. (1995) wrote that intriguing but unimportant details may distort learning in the acclimatization stage. Seductive details may recall inappropriate schemas (Harp and Mayer 1998). There is no need to include seductive details in a text (Sadoski 2001). Content relevant examples, explanatory illustrations, text cohesiveness and so on are effective ways to enhance text concreteness and interest. 
The linguistic characteristics of a text relate to its content. For example, the high percentage of familiar words indicates that the content of the text is familiar to many readers. For this connection, changes in word frequency, in the abstractness of nouns and so on, are related to changes in text content. Consequently, the recommendations for enhancing text interest lead to content that is more concrete and familiar for students.

Many of the correlation coefficients and effect sizes in the studies are large and therefore significant increase in text interest is possible if the corresponding text features are changed. However, the changes cannot be just linguistic; they should treat first of all text content. The indices of the correlation are not indisputable indicators of a cause and effect connection, which can only be based in experimental research.

The characteristics of an interesting text are interrelated and the extent of an effect includes not only the direct effect of the characteristic on text interest, but also the indirect effect. The direct effect can be studied using regression and path analysis. One example of such an analysis is given by Sadoski (2001). Regression analysis may be aimed at standardized or non-standardized coefficients. In the latter case, we will have a new reading interest formula for specific texts and students.

\section{Conclusion}

The hypothesis about the connection between the linguistic characteristics of texts and how interesting they are was on the whole supported. Text abstractness, the percentage of scientific terms, and sentence and word length were related to text interest level. The connection was stronger in the study of popular scientific texts in which the level of prior knowledge among the students was lower.

The hypothesized connection of word familiarity to text interest was supported only in one study. The percentage of words frequent in language raised student interest in popular scientific texts, but not in textbooks, where the content was more familiar to the students.

The research results enable us to make recommendations for interesting writing in science texts. The recommendations are supported by the findings of other researchers; however, the experimental verification of the recommendations is still needed.

The relatively high correlation coefficients of text characteristics with the level of interest also enable us to elaborate a text interest formula. The formula may include the percentage of abstract words and terms, average sentence length and the repeat rate of words as predictors of text interest. Computers can easily calculate these and other text characteristics and a new reading interest formula, with high predictive validity, can be included in Word processors. 
Address:

Jaan Mikk

38 Maisi Street

50407 Tartu

Estonia

E-mail: jaan.mikk@ut.ee

Tel.: +372 7424565

Fax: +372 7375156

\section{References}

Alexander, Patricia A. (2003) "The development of expertise: the journey from acclimation to proficiency". Educational Researcher 32, 8, 10-14.

Alexander, Patricia A. and Tamara L. Jetton (1996) "The role of importance and interest in the processing of text”. Educational Psychology Review 8, 89-121.

Alexander, Patricia A., Tamara L. Jetton, and Jonna M. Kulikowich (1995) "Interrelationship of knowledge, interest, and recall: assessing a model of domain learning". Journal of Educational Psychology 87, 4, 559-575.

Alexander, Patricia A., Jonna M. Kulikowich, and Sharon K. Schulze (1994) "How subject matter knowledge affects recall and interest". American Educational Research Journal 31, 2, 313 337.

Baumann, M. (1980) "Untersuchungen zur Stimulation und Motivation des Lernens durch Lehrtexte". Informationen zu Schulbuchfragen (Berlin) 40, 29-37.

Bray, Gayle Babbitt and Sheila Barron (2004) "Assessing reading comprehension: the effects of textbased interest, gender, and ability". Educational Assessment 9, 3-4, 107-128.

Campos, A., J. L. Marcos, and M. A. Gonzalez (2002) "Interest value, meaningfulness, and familiarity of words: relations with other word properties". Perceptual and Motor Skills 95, 769-775.

Dai, David Yun and Xiaolei Wang (2007) "The role of need for cognition and reader beliefs in text comprehension and interest development". Contemporary Educational Psychology 32, 3, 332-347.

Denisov P. N., V. V. Morkovkin, and Y. A. Safyan (1978) Kompleksnyi chastotnyi slovar` russkoi nauchnoi $i$ tehnicheskoi leksiki 3047 slov. [A complex frequency dictionary of Russian scientific and technical vocabulary.] Moscow: Russkii Jazyk.

Elts, Jaanus (1995) "Word length and its semantic complexity". In Family and textbooks, 115-126. Inger Kraav, Jaan Mikk, Larissa Vassiltchenko, eds. Tartu: University of Tartu.

Flesch, Rudolf (1948) “A new readability yardstick”. Journal of Applied Psychology 32, 221-233.

Furr, R. Michael (2008) Summary of effect sizes and their links to inferential statistics. Retrieved September 24, 2009 from http://psych.wfu.edu/furr/EffectSizeFormulas.pdf

Garner, Ruth, Patricia A. Alexander, Mark G. Gillingham, Jonna M. Kulikowich, and R. Brown (1991) "Interest and learning from text". American Educational Research Journal 28, 3, 643-659.

Guthrie, John T., A. Laurel W. Hoa, Allan Wigfield, Stephen M. Tonks, Nicole M., Humenick, and Erin Littles (2007) "Reading motivation and reading comprehension growth in the later elementary years". Contemporary Educational Psychology 32, 3, 282-313.

Harp, Shannon F. and Amy A. Maslich (2005) "The consequences of including seductive details during lecture". Teaching Psychology 32, 100-103.

Harp, Shannon F. and Richard E. Mayer (1998) "How seductive details do their damage: a theory of cognitive interest in science learning". Journal of Educational Psychology 90, 3, 414-434.

Harp, Shannon F. and Richard E. Mayer (1997) "The role of interest in learning from scientific text and illustrations: on the distinction between emotional interest and cognitive interest". Journal of Educational Psychology 89, 1, 92-102. 
Hidi, Suzanne (2001) "Interest, reading, and learning: theoretical and practical considerations". Educational Psychology Review 13, 3, 191-209.

Hidi, Suzanne and William Baird (1988) "Strategies for increasing text-based interest and students' recall of expository text". Reading Research Quarterly 23, 465-483.

Jetton, Tamara. L. and Patricia A. Alexander (2001) "Interest assessment and the content area literacy environment: challenges for research and practice". Educational Psychology Review $13,3,303-318$.

Klare, George R. (1963) The measurement of readability. Iowa: Iowa State University.

Laukenmann, Matthius, Michael Bleicher, Stefan Fu $\beta$, Michaela Gläser-Zikuda, Philipp Mayring, and Christoph von Rhöneck (2003) "An investigation of the influence of emotional factors on learning in physics instruction”. International Journal of Science Education 25, 489-507.

Lawless, Kimberly A. and Jonna M. Kulikowich (2006) "Domain knowledge and individual interest: the effects of academic level and specialization in statistics and psychology". Contemporary Educational Psychology 31, 1, 30-43.

Leahy, W., G. Cooper, and J. Sweller (2004) "Interactivity and the constraints of cognitive load theory". In The development and use of print and non-print text materials in diverse school settings, 89-103. A. Peacock and A. Cleghorn, eds. London: MacMillan.

Lehman, Stephen, Gregory Schraw, Matthew T. McCrudden, and Kendall Hartley (2007) "Processing and recall of seductive details in scientific text". Contemporary Educational Psychology 32, 4, 569-587.

Mikk, Jaan (2008) Sentence length for revealing the cognitive load reversal effect in text comprehension. Educational Studies 34, 2, 119-127.

Rodrigues, Maximo and M. Niaz (2004) "A reconstruction of structure of the atom and its implications for general physics textbooks: a history and philosophy of science perspective". Journal of Science Education and Technology 13, 4-20.

Sadoski, Mark (2001) "Resolving the effects of concreteness on interest, comprehension, and learning important ideas from text". Educational Psychology Review 13, 3, 263-281.

Sadoski, Mark, Ernest T. Goetz, and Joyce B. Fritz (1993) "Impact of concreteness on comprehensibility, interest, and memory for text: implications for dual coding theory and text design". Journal of Educational Psychology 85, 291-304.

Sadoski, Mark, Ernest T. Goetz, and Maximo Rodriguez (2000) "Engaging texts: effects of concreteness on comprehensibility, interest, and recall in four text types". Journal of Educational Psychology 92, 85-95.

Schiefele, Ulrich (1999) "Interest and learning from text". Scientific Studies on Reading 3, 257-279.

Schraw, Gregory, Terry Flowerday, and Stephen Lehman (2001) "Increasing situational interest in the classroom". Educational Psychology Review 13, 3, 211-224.

Singh, Kusum, Monique Granville, and Sandra Dika (2002) "Mathematics and science achievement: effects of motivation, interest, and academic engagement". The Journal of Educational Research 95, 323-333.

Sweller, John, Jeroen J. G. van Merriënboer, and Fred G. W. C. Paas (1998) "Cognitive architecture and instructional design". Educational Psychology Review 10, 251-296.

Tobias, Sigmund. (1995) "Interest and metacognitive word knowledge". Journal of Educational Psychology 87, 399-405.

4000 najbolee upotrebitel'nych slov russkogo jazyka. [4000 most often used words in Russian] (1986) Moscow: Russkij Jazyk. 